Original Article

\title{
Hypothyroidism and hyperprolactinemia in women with primary and secondary infertility
}

\author{
Shamima Bari ${ }^{{ }^{*}}$, Rokeya Begum ${ }^{2}$, Qazi Shamima Akter ${ }^{2}$ \\ ${ }^{1}$ Department of Physiology, Ibrahim Medical College, Dhaka, Bangladesh \\ ${ }^{2}$ Department of Physiology, Dhaka Medical College, Dhaka, Bangladesh
}

\begin{abstract}
Background and objectives: Infertility is a global health problem including Bangladesh. Altered thyroid and prolactin levels have been implicated as a cause of infertility. The study was undertaken to find out the serum thyroid hormones and prolactin status in women with primary and secondary infertility.
\end{abstract}

Methods: Women with primary and secondary infertility were enrolled. Fertile age-matched women were included as control. The anthropometric details (age, height and weight) were recorded. Overnight fasting blood sample was collected on 2nd day of menstrual cycle of the follicular phase. Serum thyroid stimulating hormone (TSH), free tri-iodothyronine (FT3) and free thyroxine (FT4) were measured by enzyme-linked immunosorbent assay (ELISA). Serum prolactin (PRL) was estimated by radioimmunoassay.

Results: A total of 150 women were enrolled in the study. Out of 150 women, 50 had primary and 50 had secondary infertility while 50 women were age-matched fertile women as control. The mean TSH levels of both infertility groups were significantly higher than that of fertile women. Regarding thyroid function, $24 \%$ and $28 \%$ of women with primary and secondary infertility had hypothyroidism respectively. The serum prolactin level was high in $42.9 \%$ and $50 \%$ of hypothyroid cases in primary and secondary infertility groups respectively.

Conclusion: The study has demonstrated high occurrence of hypothyroidism with raised serum prolactin levels among infertile females emphasizing the importance of estimating both serum TSH and prolactin in infertility.

IMC J Med Sci 2020; 14(1): 009. EPub date: 11 May 2020

\section{Introduction}

Infertility is an important health problem in Bangladesh. In Bangladesh, the rate of infertility has been reported as $4 \%$ to $15 \%$ [1-4]. The alteration of thyroid functions is associated with infertility [5-13]. Thyroid hormones, especially thyroid stimulating hormone (TSH), have been considered as an important component of infertility. Women with hyperprolactinemia have been found to have primary hypothyroidism. Thyroid dysfunctions interfere with numerous aspects of reproduction and pregnancy. Several articles have highlighted the association of hypothyroidism or hyperthyroidism with menstrual disturbance, anovulatory cycles, decreased productiveness and increased morbidity during pregnancy [8-10,14,15]. Hypothyroidism itself may contribute to infertility since thyroid hormones are necessary for the maximum production of both estradiol and progesterone $[12,13]$. Hence, it is necessary to screen serum thyroid hormones along with prolactin in women with infertility problems.

Therefore, the present study was undertaken to determine the status of thyroid function in women with infertility.

*Correspondence: Shamima Bari, Department of Physiology, Ibrahim Medical College, 1/A Ibrahim Sarani, Segunbagicha, Dhaka 1000, Bangladesh.Email: shamima.bari@yahoo.com 


\section{Methods}

Study design: Women with primary and secondary infertility were included in the study. Equal number of age-matched apparently healthy fertile women was enrolled as control. Primary infertility denoted those women who had never conceived. Secondary infertility was defined as the same condition developing after initial phase of fertility that means the woman conceived previously but failed to conceive subsequently [12]. The fertility was defined as the capacity to conceive.

Infertile women having husbands with normal semen analysis and those women with normal genitalia, uterus and adnexa were included. Women with tubal factor, congenital anomaly of urogenital tract and any obvious organic lesion or pelvic inflammatory diseases, and lactating women and also infertile women with subclinical hypothyroidism, secondary hypothyroidism were and subclinical hyperthyroidism, secondary hyperthyroidism were excluded from this study; only primary hypothyroidism and primary hyperthyroidism were included.

The purpose and benefits of the study were explained to each participant and informed written consent was taken from each of them. A detailed medical, drug, personal, family, socio-economic histories were recorded in a predesigned questionnaire. The study was approved by the Institutional Ethical Review Committee.

Collection of blood and estimation of biochemical parameters: Aseptically 5 milliliter of blood was collected from cubital vein of each participant. Blood was allowed to clot for 30-60 minutes at room temperature and then centrifuged at 3000 rpm for 5-10 minutes. The serum was separated and preserved at $-20^{\circ} \mathrm{C}$ for estimation of serum TSH, FT4, FT3 and prolactin. The thyroid hormones were measured by enzyme-linked immunosorbent assay (ELISA) and serum prolactin was estimated by radioimmunoassay. The analysis was done within 2 weeks of blood collection. The normal range of serum, TSH, FT4, FT3 and prolactin were 0.3-4.0 $\mathrm{mIU} / \mathrm{L}, 10.3-24.5 \mathrm{pmol} / \mathrm{L}, 2.3-6.3 \mathrm{pmol} / \mathrm{L}$ and $2-25$ $\mathrm{ng} / \mathrm{ml}$ respectively.

Operational definition: The study population was categorized as (a) euthyroidism when the values of TSH and FT4 were within the normal range, (b) hypothyroidism when the TSH value exceeded 4.0 $\mathrm{mIU} / \mathrm{L}$ and the FT4 value was normal or low, and (c) hyperthyroidism when the TSH value was $<0.1$ $\mathrm{mIU} / \mathrm{L}$ or undetectable and normal or elevated FT3 or FT4 value $[16,17]$.

Statistical Analysis: The data were analyzed by appropriate statistical tests namely, one way ANOVA, Tukey's HSD post-hoc test and unpaired student's t test and $\mathrm{Z}$ test.

\section{Results}

A total of 150 women were included in the study. Out of 150 enrolled participants, 50 had primary (Group A) and another 50 had secondary infertility (Group B). Fifty age-matched apparently healthy fertile women were enrolled as control (Group C). The age range of the study population was from 23 years to 34 years and the mean age of different groups was almost similar and no statistically significant difference was observed. There was no

Table-1: Serum TSH, FT4, FT3 and prolactin levels of study population

\begin{tabular}{lccccc}
\hline $\begin{array}{c}\text { Study } \\
\text { population }\end{array}$ & No. & \multicolumn{4}{c}{ Mean \pm SE serum level of } \\
\cline { 2 - 5 } & & $\begin{array}{c}\text { TSH } \\
\text { (mlU/L) }\end{array}$ & $\begin{array}{c}\text { FT4 } \\
\text { (pmol/L) }\end{array}$ & $\begin{array}{c}\text { FT3 } \\
\text { (pmol/L) }\end{array}$ & $\begin{array}{c}\text { Prolactin } \\
\text { (ng/ml) }\end{array}$ \\
\hline Group A & 50 & $4.83 \pm 0.54$ & $10.54 \pm 0.66$ & $4.12 \pm 0.32$ & $14.54 \pm 1.23$ \\
Group B & 50 & $6.40 \pm 0.59$ & $7.64 \pm 0.44$ & $3.9 \pm 0.23$ & $15.36 \pm 1.02$ \\
Group C & 50 & $1.98 \pm 0.18$ & $14.48 \pm 0.64$ & $4.93 \pm 0.20$ & $10.58 \pm 0.71$ \\
\hline
\end{tabular}

Note: GrA = Primary infertility, GrB = Secondary infertility, GrC = Control; For TSH - GrA vs GrC: $p<0.001$, GrB vs GrC: $p<0.001$, GrA vs GrB: $p=0.05$; For FT4 - GrA, GrB and GrC were significantly different from each other: $p<0.005$; For FT3 - GrA vs GrC: $p=0.03$, GrB vs GrC: $p=0.001$, GrA vs GrB: $p=0.58$; For prolactin - GrA vs GrC: $p=0.017$, GrB vs GrC: $p=0.003$, GrA vs GrB: $p=0.834$. One way ANOVA and Tukey's post-hoc tests were performed to compare among the groups. 
Table-2: Thyroid function status and prolactin levels in women with primary and secondary infertility

\begin{tabular}{|c|c|c|c|c|}
\hline \multirow[t]{2}{*}{ Study population } & \multirow[t]{2}{*}{ Number (\%) } & \multirow{2}{*}{$\begin{array}{l}\text { Mean } \pm \text { SE serum TSH } \\
(\mathrm{mlU} / \mathrm{L})\end{array}$} & \multicolumn{2}{|c|}{ Serum prolactin level } \\
\hline & & & $\begin{array}{l}\text { High } \\
\mathrm{N}(\%)\end{array}$ & $\begin{array}{c}\text { Normal } \\
\mathrm{N}(\%)\end{array}$ \\
\hline \multicolumn{5}{|l|}{ Group A $(n=50)$} \\
\hline Euthyroid & $35(70)$ & $3.12 \pm 0.21$ & $2(5.7)$ & $33(94.3)$ \\
\hline Hypothyroid & $14(28)$ & $5.14 \pm 0.85$ & $6(42.9)$ & $8(57.1$ \\
\hline Hyperthyroid & $1(2)$ & - & 0 & $1(100)$ \\
\hline \multicolumn{5}{|l|}{ Group B $(n=50)$} \\
\hline Euthyroid & $36(72)$ & $4.12 \pm 0.16$ & $1(2.7)$ & 35 (97.3) \\
\hline Hypothyroid & $12(24)$ & $7.97 \pm 0.72$ & $6(50)$ & $6(50)$ \\
\hline Hyperthyroid & $2(4)$ & $1.07 \pm 1.04$ & 0 & $2(100)$ \\
\hline \multicolumn{5}{|l|}{ Group C $(n=50)$} \\
\hline Euthyroid & $50(100)$ & $1.98 \pm 0.18$ & 0 & $50(100)$ \\
\hline
\end{tabular}

Note: High prolactin $=>25 \mathrm{ng} / \mathrm{ml}$; $Z$ test was performed; GrA vs GrB with euthyroid: $Z=0.82, p=0.22$;

GrA vs GrB with hypothyroid: $Z=0.45, p=0.54 ;$ GrA vs GrB with hyperthyroid: $Z=0.580, p=0.55$.

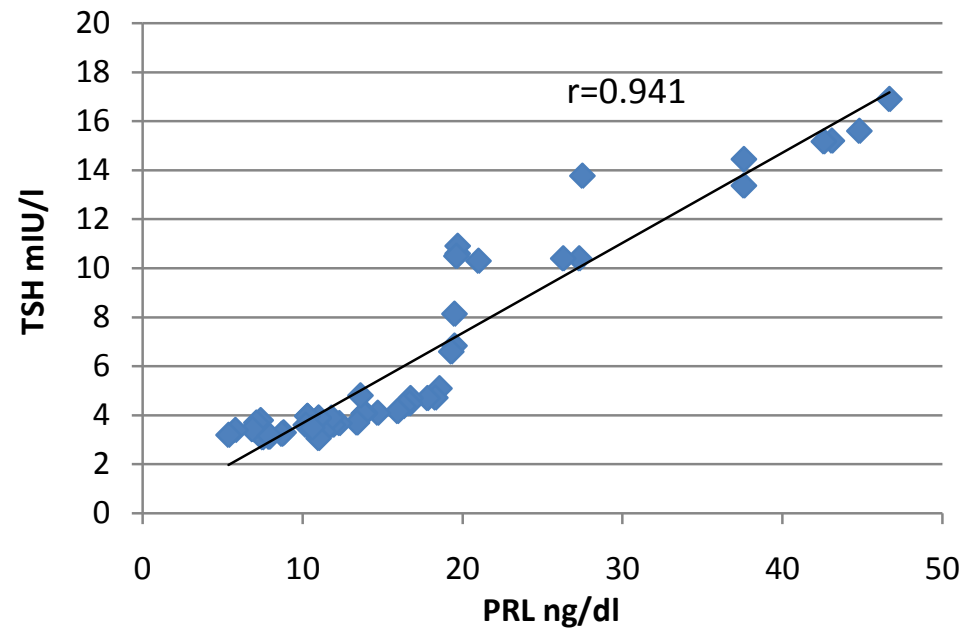

Figure-1: Correlation of serum prolactin with TSH in primary infertile women

significant difference of mean body mass index (BMI) between Group A and B.

The mean serum levels of TSH, FT4, FT3 and prolactin of Group A, B and C are shown in Table-1. The mean serum TSH levels of women with primary $(4.83 \pm 0.54 \mathrm{mIU} / \mathrm{L})$ and secondary $(6.40 \pm 0.59$ $\mathrm{mIU} / \mathrm{L})$ infertility were significantly $(\mathrm{p}<0.001)$ higher than that of women with normal fertility $(1.98 \pm 0.18$ $\mathrm{mIU} /$ ). The mean serum FT4 levels of women with primary $(10.54 \pm 0.66 \mathrm{pmol} / \mathrm{L})$ and secondary $(7.64 \pm 0.44 \mathrm{pmol} / \mathrm{L})$ infertility were significantly $(p<0.005)$ lower than that of women with normal fertility $(14.48 \pm 0.64 \mathrm{pmol} / \mathrm{L})$. The mean serum FT3 levels of women with primary $(4.12 \pm 0.32 \mathrm{pmol} / \mathrm{L})$ and secondary infertility $(3.9 \pm 0.23 \mathrm{pmol} / \mathrm{L})$ were significantly $(p=0.03$ and $p=0.001)$ lower than that of women with normal fertility $(4.93 \pm 0.20 \mathrm{pmol} / \mathrm{L})$. There was no significant difference of serum FT3 between Group A and B. Mean serum prolactin levels of women with primary $(14.54 \pm 1.23 \mathrm{ng} / \mathrm{ml})$ and secondary $(15.36 \pm 1.02 \mathrm{ng} / \mathrm{ml})$ infertility were significantly $(p<0.05)$ higher than that of women with normal fertility $(10.58 \pm 0.71 \mathrm{ng} / \mathrm{ml})$. However, no significant difference was observed between women with primary and secondary infertility. 


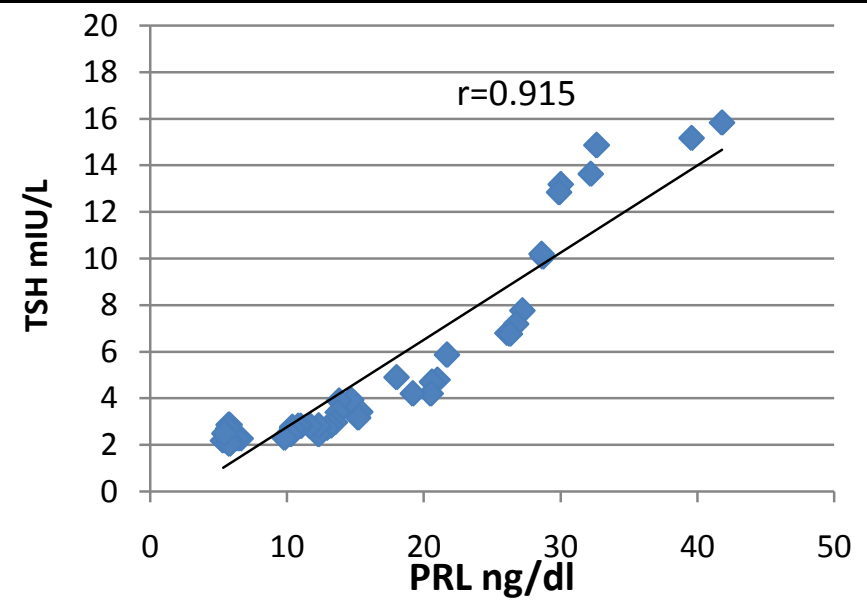

Figure-2: Correlation of serum prolactin with TSH in secondary infertile women

According to the thyroid function status, $70 \%$ and $72 \%$ of the women having primary and secondary infertility were euthyroid respectively while $28 \%$ and $24 \%$ were suffering from hypothyroidism (Table-2). All the women in control group were euthyroid. Primary hyperthyroidism was present in $2 \%$ and $4 \%$ women with primary and secondary infertility (Table-2). The mean serum TSH level of hypothyroidism cases $(7.97 \pm 0.72 \mathrm{mIU} / \mathrm{L})$ of secondary infertility was significantly higher $(p=0.02)$ compared to hypothyroidism cases of primary infertility group (5.14 $\pm 0.85 \mathrm{mIU} / \mathrm{L})$. High serum prolactin level was observed in $42.9 \%$ and $50 \%$ cases with hypothyroidism of women with primary and secondary infertility.

The Pearson's correlation coefficient was calculated for serum TSH and prolactin in primary and secondary infertile women. In primary infertile women serum prolactin levels were significantly positively correlated with corresponding TSH levels ( $r=0.941, p<0.001$; Figure-1). In secondary infertile women, serum prolactin levels also showed significantly positive correlation with serum TSH levels ( $r=0.915, p<0.001$, Figure-2). Hence, there was a strong association observed in primary and secondary infertile women with hyperprolactinemia and hypothyroidism.

\section{Discussion}

Thyroid dysfunction and alteration of prolactin levels have been reported as the cause of female infertility [8-10,15,18-23]. In the present study, hypothyroidism was found in $24 \%-28 \%$ women with primary and secondary infertility. Such pattern of thyroid dysfunction was also reported by several studies [8-15,18,20-22,24]. In hypothyroidism, increased thyrotropin-releasing hormone (TRH) production stimulates both TSH and prolactin secretion [23] and that leads to hyperprolactinemia and altered gonadotropin-releasing hormone $(\mathrm{GnRH})$ secretion. This leads to a delay in luteinizing hormone (LH) response and inadequate corpus luteum leading to abnormal follicular development and ovulation [8-15,18,20-24].

High prolactinemia is the commonest biochemical abnormality observed in infertility [25]. Furthermore, prolactin may affect the ovaries by altering ovarian progesterone secretion and estrogen synthesis leading to infertility $[23,25]$. Women with high level of prolactin may ovulate regularly but may not produce enough progesterone during luteal phase after ovulation. Deficiency of progesterone produced after ovulation, may hamper embryo implantation in a uterine lining $[26,27]$. Hyperprolactinemia resulting from longstanding primary hypothyroidism has been implicated in ovulatory dysfunctions [23].

In infertile females if hypothyroidism is associated with hyperprolactinemia, hypothyroidism should be treated first and TSH should be maintained at lower limit. Evidence from experimental and clinical studies has suggested a close relationship 
between the hypothalamic-pituitary-ovarian axis (HPO) and the hypothalamic-pituitary-thyroid axis (HPT) [13,26-28]. This is because, the specific thyroid hormone receptors at the ovarian level may regulate the influence of estrogens as well as reproductive function at higher levels of the HPT axis thereby integrating the reciprocal relationship between these two major endocrine axis [24]. Hyperprolactinemic patients without any sign of pituitary dysfunction have normally reduced levels of thyroid hormones. We found that about $50 \%$ of our hypothyroid cases had hyperprolactinemia. Similar observation have been reported by others [7,8,15,20,29-31].

Therefore, the present study has demonstrated that a significant number of women with primary and secondary infertility have altered thyroid function and serum prolactin levels compared to fertile women.

\section{Acknowledgement}

Authors of this study are thankful to Dr. Sanwar Hossain, Director, Centre for Nuclear Medicine and Ultrasound, Dhaka Medical College, Dhaka for his sincere cooperation.

\section{References}

1. Sala Uddin GM, Wahed MII, Haque A, Nejum MR. Current Consequence and Research of Human Infertility in Bangladesh. J Reproductive Endocrinol \& Infert. 2018; 3(1):4.

2. Farely TMM, Baisey EM. The prevalence of an etiology of infertility. Proceedings of the $1^{\text {st }}$ African Population Conference. 28 November 1998; Senegal, Dakar; 1998

3. Nahar P. Invisible women in Bangladesh: stakeholder's view on infertility services. Facts Views Vis Obgyn. 2012; 4(3): 149-156.

4. Vaessen M. Childlessness and infecundity. WFS Comparative Studies, Series 31. Voorburg, The Netherlands: Cross National Summaries, 1984.

5. Cramer DW, Sluss PM, Powers RD, McShane P, Ginsburgs ES, Hornstein MD, et al. Serum prolactin and TSH in an in vitro fertilization population: is there a link between fertilization and thyroid function? J Assist Reprod Genet. 2003; 20(6): 210-215.

6. Roupa Z, Polikandrioti $M$, Sotiropoulou P, Faros E, Koulouri A, Wozniak G. Causes of infertility in women at reproductive age. Health Sci J. 2009; 3: 80-87.

7. Avasthi K, Kaur J, Shweata G, Pal AN. Hyperprolactinemia and its correlation with hypothyroidism in infertile woman. J Obs Gyn India. 2007; 56(1): 68-71.

8. Akhter N, Hassan, MA. Subclinical hypothyroidism and hyperprolactinaemia in infertile women: Bangladesh perspective after universal salt iodinisation. The internet $J$ Endocrinol. 2009; 5(1): 1-5.

9. Emokpae MA, Osadolor HB, Omole Ohonsi A. Sub-clinical hypothyroidism in infertile Nigerian women with hyperprolactinaemia. Nig J Physiol Sci. 2011; 26: 35-38.

10. Tasneem A, Fatima I, Ali A, Mehmood N, Amin MK. The incidence of hyperprolactinaemia and associated hypothyroidism: local experience from Lahore. Pak J Nuclear Med. 2011; 1: 4955 .

11. Poppe K, Velkeniers B, Glinoer D. Review: Thyroid disease and female reproduction. Clin Endocrinol (Oxf). 2007; 66(3): 309-321.

12. Doufas AG, Mastorakos G. The hypothalamicpituitary-thyroid axis and the female reproductive system. Ann N Y Acad Sci. 2000; 900(1): 65-76.

13. Turankar S, Sonone K, Turankar A Hyperprolactinaemia and its comparison with hypothyroidism in primary infertile women. J Clin Diagn Res. 2013; 7(5): 794-796.

14. Iris A, Kawuwa MB, Habu SA, Adebayo A. Prolactin levels among infertile women in Maiduguri, Nigeria. Trop J Obs Gyn. 2003; 20: 97-100.

15. Thirunavakkarasu K, Dutta $P$, Sridhar $S$, Dhaliwal L, Prashad GRV, Gainder S, et al. Macroprolactinemia in hyperprolactinemic infertile women. Endocrine. 2013; 44: 750-755.

16. Dayan CM. Interpretation of thyroid function tests. Lancet. 2001; 357(9256): 619-624. 
17. Jameson J. Disorders of the thyroid gland. In: Fauci A, Braunwald E, Kasper D, Houser S, Longo D, Jameson J, editors. Harrison's Principles of Internal Medicine. New York: McGraw-Hill; 2008. pp. 2224-2246.

18. Mishra R, Baveja R, Gupta V, Gupta P. Prolactin level in infertility with menstrual irregularities. J Obs Gyn India. 2002; 52: 40-43.

19. Choudhary SD, Goswami A. Hyperprolactinemia and reproductive disorders - a profile from north east. J Assoc Phy India. 1995; 43: 617-618.

20. Olooto WE, Adeleye AO, Amballi AA, Mosuro AO. Pattern of reproductive hormones (follicle stimulating hormone, luteinizing hormone, estradiol, progesterone, and prolactin) levels in infertile women in Sagamu South Western Nigeria. Der Pharmacia Lettre. 2012; 4(2): 549-553.

21. Pratibha D, Govardhani M, Krihna PT. Prolactin levels in infertility and bromocriptine therapy in hyperprolactinemia. J Indian Med Assoc. 1994; 92(12): 397-399.

22. Parijatham S, Saikumar P. Serum levels of follicle stimulating hormone, luteinizing hormone and prolactin in primary female infertility in rural population. Res J Pharm Bio Chem Sci. 2014; 5(2): 1155-1158.

23. Mancini T, Casanueva FF, Giustina A. Hyperprolactinemia and prolactinomas. Endocrinol Metab Clin North Am. 2008; 37(1): 67-69.
24. Azima K, Samina J. Role of hyperprolactinemia in fertility. Pakistan J Med. 2002; 3: 41.

25. Elahi S, Tasneem A, Nazir I, Nagra SA, Hyder SW. Thyroid dysfunction in infertile women. J Coll Physicians Surg Pak. 2007; 17(4): 191-194.

26. Surks MI, Ortiz E, Daniels GH. Subclinical thyroid disease: scientific review and guidelines for diagnosis and management. JAMA. 2004; 291(2): 228-238.

27. Armada-Dias L, Carvalho JJ, Breitenbach MM, Franci CR, Moura EG. Is the infertility in hypothyroidism mainly due to ovarian or pituitary functional changes? Braz J Med Biol Res. 2001; 34 (9): 1209.

28. Krassas GE. Thyroid disease and female reproduction. Fertil Steril. 2000; 74(6): 10631070.

29. Goswami B, Patel S, Chatterjee M, Koner BC, Saxena A. Correlation of prolactin and thyroid hormone concentration with menstrual patterns in infertile women. J Reprod Infertil. 2009; 10(3): 207-212.

30. Singh L, Agarwal CG, Chowdhary SR. Thyroid profile in infertile women. J Obstet Gynecol India. 1990; 40: 248-253.

31. Verma I, Sood R, Juneja S, Kaur S. Prevalence of hypothyroidism in infertile women and evaluation of response of treatment for hypothyroidism on infertility. Int J Appl Basic Med Res. 2012; 2(1): 17-19. 